\title{
Implementation of an integrated reflective practice model in higher education pedagogy within the context of a South African tertiary institution
}

\author{
Petronella Jonck ${ }^{\star} \bullet$ Riaan De Coning
}

Research and Innovation, The National School of Government, 70 Meintjies Street, Sunnyside, Pretoria, South Africa.

*Corresponding author. E-mail: petrojonck@hotmail.com. Tel: 0712995162.

Accepted 29 $9^{\text {th }}$ October, 2018.

\begin{abstract}
Reflection as educational tool to improve practice has gained impetus and is deemed critical within the context of culturally relevant pedagogy. This article provides an example of a practitioners' reflection on applied educational practices within the context of a South African tertiary institution based on the Comprehensive Assessment Method in Psychology (CAMP). A qualitative, phenomenological research design was implemented. The CAMP model was found to be useful ascribed to the ability thereof to distil and integrate the key academic focus areas with student feedback. In addition, the researcher reflected on underlying beliefs and assumptions which guide internalised interest and practice in the field of education. The significance of the study underscores the value of reflection for current or prospective career academics in terms of aligning with institutional strategic intent. Moreover, it gauges the measure of potential misalignment as well as identifying developmental areas for educators.
\end{abstract}

Keywords: Educational policy, higher education, institutional alignment, reflection.

\section{INTRODUCTION}

Reflection as a tool for improving educational practice has gained prominence over the last decade. Despite the stated emphasis, the body of knowledge predominantly focuses on theoretical aspects resulting in a paucity of practical implementation examples (Merryfield, 1993). According to Howard (2003) the significance of especially critical reflection (viz. examining the context of the implemented pedagogy against the internalised frame of reference of the practitioner as per Mezirow (1998) is related to the recommendation thereof as a method for incorporating controversial topics such as equity and social justice into teaching thinking and practice. Likewise within the context of globalization and the imminence of the fourth industrial revolution, a global perspective on education is essential. As such, global education involves both knowledge and perception since New Millennium learners are endowed with internalised attitudes, beliefs and insights about the expected learning experiences which could potentially influence the acquisition and processing of knowledge (Groff, 2013). Various authors, for example Saltiel (2007), Bourner (2003), Lewis, Virden, Hutchings and Bhargava (2011) as well as Mälkki and Lindblom-Ylänne (2012) noted that within the context of higher education, reflection has become keystone to quality teaching and professional development. In addition to the paucity of practical examples, little empirical research exists emphasizing the link between lecturers' reflection and action, which determine the extent to which the practitioners' reflection-based views are implemented to the benefit of students (Mälkki and Lindblom-Ylänne, 2012). Another fissure in the body of knowledge relates to the utilization of reflective practices 
to ensure institutional alignment between teaching practice and organizational strategic intent.

In light of the aforementioned the research reported on, aimed to implement an integrated reflective practice model that was developed internationally for psychology within the context of academic teaching endeavours in the mentioned field.

\section{Conceptualizing reflection}

The concept of reflection is deemed as intangible and ambiguous, with little guidance as to determining, nurturing and assessing the practice thereof (Leijen et al., 2012). Reflection can by and large be defined as a cognitive process executed in order to learn from experiences (Moon, 2013) thereby fostering more complex and integrated knowledge structures resulting in accessible and usable knowledge (Billings, 2007). Dewey (1997:6) defined reflection as "active, persistent, and careful consideration of any belief or supposed form of knowledge in the light of the grounds that support it, and the further conclusions to which it tends". According to the pragmatists' perspective, reflection serves the purpose of becoming conscious and thoughtful about overt behaviour (Rodgers, 2002). As such, reflection is an integral stage in the experiential learning cycle of Kolb (1984) which is considered a predominant conceptual underpinning for adult learning (Bourner, 2003).

According to Lewis et al. (2011), Dewey and Schön are two seminal authors on the subject of reflection. As per Dewey, two kinds of experiences can be distinguished, namely unreflective experiences and reflective experiences. Unreflective experiences refer to behaviour based on trial and error while, reflective experiences underscore a deliberately fostered mode of thinking aimed at discovering the connection between actions and outcomes (Dewey, 1916).

Furthermore, the depth of reflection should also be briefly highlighted. Kember et al. (1999) identified seven types of reflection operating on varying levels of complexity, namely habitual action, introspection, thoughtful action, content reflection, process reflection, a combination of content and process reflection and premise reflection. Mezirow (1998) defines premise reflection as the process through which individuals become aware of their internalized frame of reference consisting of unconscious beliefs and values which ascribe meaning to experiences. Thus, premise reflection in essence refers to reflecting on the underlying assumptions which provide the impetus for overt behaviour fortified by the question posed: Why am I doing what I am doing? Premise reflection can also be referred to as critical reflection. Critical reflection is an inherent component of critical pedagogy. The primary difference between the mentioned levels of complexity is that it distinguishes between two sub-divisions, namely non- reflective action and reflective thinking. Habitual action, introspection and thoughtful action are categorised under non-reflective action. Content reflection (underscoring what happened), process reflection (focusing on the how question), and premise reflection (emphasizing why) are part and parcel of reflective learning (De Coning, 2014). Bourner (2003) describes reflective learning as the missing link between experience and learning, thus developing the capacity to learn how to learn.

\section{Practical application}

Mälkki and Lindblom-Ylänne (2012) assert that the relevance of reflection to the practice of higher education teaching has been researched extensively. Leitch and Day (2000) elaborated by indicating that reflective practices entail making conscious and explicit the dynamic interplay between cognitive processing and behaviour which has fittingly been coined the 'wisdom of teaching' by Shulman (1987). Indeed, Bourner (2003) noted that within the higher education milieu, Schön's (1983) notion of reflective practitioner has been especially influential.

Pursuantly, in educational programs, imparting knowledge and developing skills are necessary but insufficient. As such, the epitome of teaching practice is perceived as creating an enabling environment that assist students, to not only develop minimum competence in identified areas requisite to a specific occupation, but to aim for what is coined as artistry. In other words, outstanding prospective practitioners are not seen as having supplementary theoretical knowledge in comparison to peers, but are described as wise, talented, and intuitive, more aptly, artists (Lewis et al., 2011). The notion of artistry also rings true for higher education teaching. As such, Bourner (2003) noted that the role of reflection is increasing irrespective whether higher education is preparing students for lifelong learning, delivering continuous development or preparing academics for teaching at tertiary institutions. In order to enhance artistry, reflection-on-action, which consists of thinking back on behaviour in order to comprehend how knowing-in-action resulted in certain outcomes, is cornerstone (Schön, 1987). Leitch and Day (2000) define knowing-in-action as cognitive processing which accompany action thus constantly interacting with and modifying ongoing practice to facilitate learning.

The aforementioned authors furthermore pointed out that reflection is keystone to ensure that educators reflect on the social, economic and political circumstances of teaching and the classroom contexts (Leitch and Day, 2000). As such, Brookfield (1995) noted that the economic, social, and political context of the environment internalized by means of laws, codes and policies form underlying assumptions (viz. hegemonic assumptions) which influences the power relationship between the 
educator and students. Critical reflection is thus aimed at unmasking the tacit hegemonic assumptions that reproduce systems of class, race, and gender inequality. Therefore, in order to strive towards social justice, critical reflection is required by the lecturer to ensure their actions do not contribute to preserving the status quo (Mortari, 2015). However, the link between reflection and behavioural change is not self-evident. Thus, critical reflection would only achieve the objective as indicated if the aforementioned result in transformation (Mezirow, 2008).

\section{Assessing reflection}

Bourner (2003) identified the chief impediment to assessing reflective practices as the subjective nature thereof as only the individual can determine whether the learning that occurred was significant. The second substantial weakness centres on the nature of assessment which involves a judgement of the extent to which planned learning outcomes has been achieved. While, learning that emanate as a result of reflective practices is emergent in nature (Bourner, 2003). To circumvent the mentioned stumbling blocks a Comprehensive Assessment Method in Psychology (CAMP) has been proposed and implemented internationally (Lewis et al., 2011). The CAMP consists of 35 diverse authentic work products representing a variety of assessment techniques which are founded on pedagogical theory. Portfolios and self-reflection/selfregulation exercises are the two main components of the CAMP (Lewis et al. 2011).

\section{RESEARCH METHODOLOGY}

Reflection is pivotal to cognitive practices in research as discipline especially in qualitative research designs (Dahlberg et al., 2008). Per se, a qualitative phenomenological inquiry was utilized as research design which has as objective investigating the lived experiences of respondents. Implementing phenomenological reflection means to activate introspection, in order to grasp unreflective mental experiences and to give voice to it, in order to comprehend its essence (Varela et al., 1991).

Pursuant to the discussion in the preceding section the research procedure was in line with the Comprehensive Assessment Method in Psychology (CAMP) framework especially since psychology can be considered as contextually relevant. As the implementation of the CAMP model was the aim of the research, it reported on the two main categories that were identified, namely a selfreflection exercise and a portfolio of evidence. The selfreflection exercise focused on content and premise or critical reflection, while the portfolio of evidence underscored process reflection. Lombardi (2008) noted that education underscore both products and processes. Examples of educational products subsume academic journal articles as well as written assessments, to mentioned a few. Process refers to comprehending the context of teaching and learning (Lewis et al., 2011). Hence, the self-reflection exercise highlighting content reflection was based on the academic articles authored by the lecturer. More specifically, conducting thematic analysis on the research outputs of the last mentioned. In addition, the premise or critical reflection explored the hegemonic assumptions of the lecturer by means of examples. The portfolio of evidence which specifically focused on process reflection explored the application of teaching and learning by means of the implementation of a student evaluation questionnaire.

The sample utilized with reference to the portfolio of evidence consisted out of $48(n=48)$ respondents from a population of 110 Honours degree research methodology students. A two-tailed data collection procedure was implemented. Firstly, a list of all the subjects lectured at a higher education institution was obtained. From the list a random sample of subjects was drawn. Secondly, consent forms and data collection instruments were distributed to students attending a day lecture. Convenient sampling was utilised since participants that were present at the lecturing venue on a specific day were included. Data was collected using a Student Evaluation of Teaching and Course Content Questionnaire developed based on a model by Van der Merwe (2007) emphasizing student evaluation in order to enhance teaching and learning quality. The research procedure followed was initiated and implemented by the institutional monitoring unit of a higher education institution. The lecturer was informed about the pending student evaluation and requested to introduce the field workers at the commencement of the lecture and afterwards to depart. Data capturing was done at an institutional level and made available to the lecturer on request. In addition to the evidence obtained from the questionnaire, the teaching profile also consists of reference letters from two postgraduate students as well as two colleagues. One of the aforementioned being an international collaborator and co-supervisor of doctoral candidates. In terms of analysis, thematic content analysis was utilized analysing the narrative of respondents. All ethical protocol was observed.

As qualitative research lend itself towards bias an acknowledged caveat that should be taken into consideration is that the research reported on is an example of self-reflection and a portfolio of evidence based on an institutional monitoring and evaluation process and therefore subject towards bias. To increase the rigour of the research reported on the themes identified in the portfolio of evidence were in line with the accepted objectives of a Teaching and Learning Strategy taken from one of the foremost universities in the South 


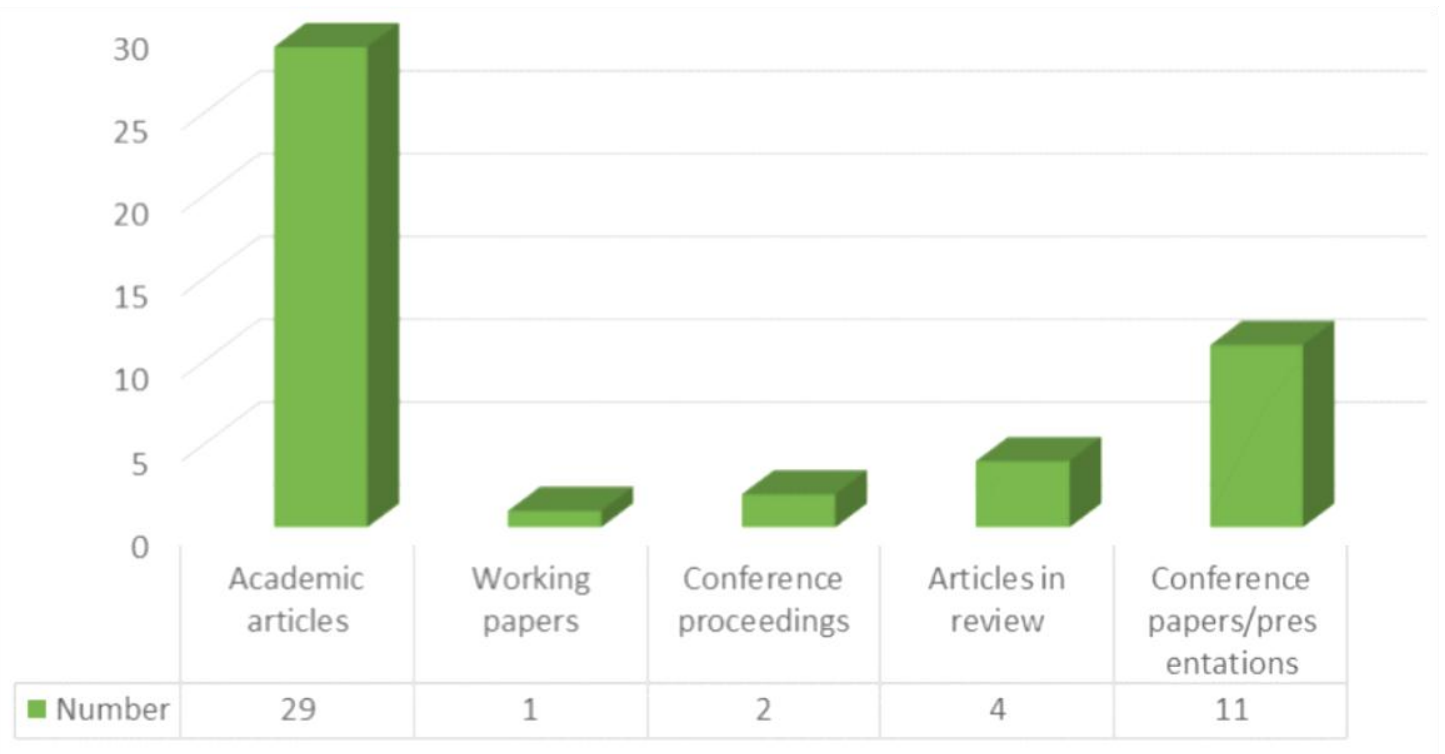

Figure 1. Research outputs to date.

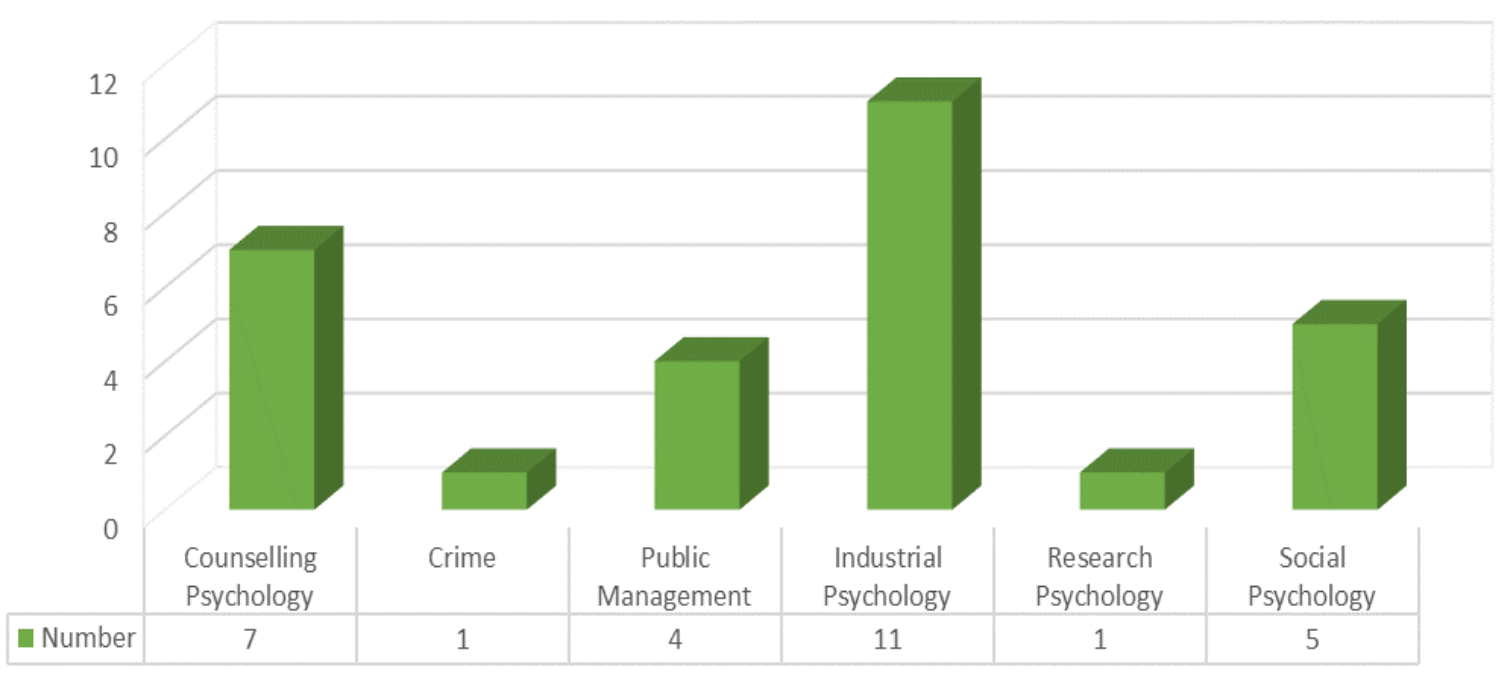

Figure 2. Thematic analysis of published articles.

African context as benchmark. Secondly, researcher triangulation was utilized as a registered business coach guided the lecturer in the reflection process and the interpretation thereof.

\section{RESULTS}

To provide a lens through which to examine the qualitative data three categories of reflection were utilized subsuming content reflection (based on a self-reflection exercise), process reflection (as determined by a portfolio of evidence), and premise reflection (emphasizing the hegemonic assumption).

\section{Content reflection}

With reference to content reflection the research outputs of the lecturer could be used as reference. Figure 1 contains an overview of the research outputs to date.

Figure 1 indicates that the author's focus was mainly on academic journal articles and conference papers. An analysis of the main themes which eminated from the published academic articles is illustrated in Figure 2.

Figure 2 points to Psychology as the main focus area of the author with a total number of twenty three (23) articles of which eleven (11) were related to Industrial Psychology, seven (7) focusing on Counselling Psychology and five (5) articles within the Social 
Psychology classification.

More specifically, the lecturers' on-going research agenda focus on two global problem areas subsuming educational change and social justice. A summary of the first sub-theme, namely educational change will be briefly highlighted after which the second sub-theme will sequentially be addressed.

\section{Educational change}

In terms of the first theme, education is vital in the emerging knowledge economy which as commodity is rapidly accredited, replacing raw materials and labour as the most critical input for determining the progress of a country's labour force - at an economic as well as a social level - therefore the country's ability to compete in the world economy (Goujon et al., 2011). Higher education enhances a country's capacity for partaking in an increasing knowledge-based world economy and has the potential to amplify economic growth and reduce poverty. Education at large is also an important determinant of human capital formation (Jonck and Van der Walt, 2015). Within this broad classification three sub-themes were identified. Firstly, changing the educational composition of the population; secondly, the expansion of higher education and formation of skills have been top priorities in many developing economies, including South Africa, which is typically described as scarce of skilled labour. The focus area of this sub-theme was youth unemployment, especially graduate unemployment in light of skills shortages. Thirdly, recent research underscores the importance of educational quality, and the increased emphasis on educational attainment. With this in mind the researcher undertook various projects that focus on these three aspects of human capital formation within the broad theme of educational change.

Changing the educational composition of the population: In terms of the first sub-theme relating to the educational composition of the population, South Africa's skills shortages have been deemed a 'national crisis' in light of the fact that almost every sector of the South African economy experiences a shortage to some extent. Skills shortages pose a significant obstacle to the country's long term economic growth potential since viable economic opportunities cannot be productively cultivated. The aforementioned is widely regarded as a key factor preventing the achievement of targeted economic growth rates in South Africa (Erasmus and Breir, 2009). Key issues raised by research which might significantly influence skills shortages include amongst other the minute amount of African grade 12 learners who qualify for admission to higher education programs. In order to change the educational composition of the South African population the participation rate of higher education must be increased, together with the formation of the required skilled labour needed by the labour market. A lack of effective career guidance at secondary school level can be cited as a main contributor which adversely affect participation rate in higher education programs as well as create skills shortages since learners lack the required subjects for careers in the hard sciences (engineering, science and technology). Against this background one possible way for South Africa to address its debilitating labour shortages as well as change the educational composition of the population is to provide effective career counselling at secondary school level. It is of the utmost importance that learners should be adequately informed about vocational availability as well as subject requirements. Pursuantly, a research project aimed to investigate the effectiveness of career guidance provided at secondary school level was undertaken. Several articles have been published from the mentioned research project.

Graduate unemployment: Relating to the second subtheme an increase in the participation rate of higher education however might lead to an increase in the graduate unemployment rate. When there is an increase in the supply of graduates, there is a concomitant increase in the skills requirement since the labour market becomes saturated with lower skilled employees. This causes an elevation of the skills premium which refers to the difference between the income generated by skilled and unskilled employees - price - which in turn results in accelerated economic growth. This tendency manifests as a global trend. Research on the (adverse) effects of expanding higher education found that as a result of the expansion of the demand for higher education, new educational policies are adopted which increase the supply of graduates (Oppedisano, 2011). An increase in the supply influence enrolment as well as dropout rates and academic performance which in turn have a direct influence on higher education institutions performance and indirectly affects graduates labour market outcomes. International research found that the number of graduates entering the labour market increased. This rapid expansion produced an unparalleled number of graduates whose employment prospects are uncertain which sequentially result in rising graduate unemployment (Jonck, 2014). Within the South African context, the unemployment rate of graduates increased by an estimated 50\% between 1995 and 2005, which makes it the fastest growing unemployment rate (Development Policy Research Unit, 2007). A research project ensued to investigate this phenomenon with a book chapter, conference papers and academic journal articles as research outputs to date.

Improving educational quality: Concerning the third sub-theme, namely improving educational quality, the human capital theory has allowed economist, policy 
makers and stakeholders at large to create a skewed faith in the 'education gospel', which argues that higher levels of education result in increased access to the labour market as well as higher levels of economic earnings. This mantra is a fallacy. Research indicated that there was no statistically significant association between skills development in higher education institutions and increased probability of employment (Hinchliffe and Jolly, 2011). Hence, there appears to be a growing discrepancy between the book value and the market value of qualifications as commerce and industry are increasingly setting exact requirements with regard to knowledge and skills. As such, commerce and industry are the primary customers of graduates' produced by Higher Education Institutions. In order to remain relevant in addition to improving educational quality higher education must stay informed of and adjust curricula to meet the demands of ever-changing employer market requirements (Jonck and Minnaar, 2015). With this in mind, a research project was undertaken to ensure that graduates are employable and ultimately meet the expectations of employers. Pursuantly, a quantitative research design was implemented by utilizing a questionnaire as measuring instrument to gather data on how employers evaluate graduates' employability skills. Three supplementary research projects were undertaken under the ambit of this sub-theme, namely higher education reform initiatives in Africa, and determining the quality of postgraduate research supervision. Of late the paucity of research skills particularly in the field of quantitative research was noted. As a result, several training interventions have been undertaken besides determining the impact of the mentioned intervention.

\section{Social justice}

The second thematic area refers to a stance towards making society more equitable (Crucil and Amundson, 2017). The main objective of social justice through the lens of psychology would be to address the social, political, and economic conditions that impede on the academic, career, and personal/social development of individuals, families, and communities (Ratts, 2009). Gender inequality, which can be perceived as a social justice impediment, has been included in the Millennium Development Goals as well as the Sustainable Development Goals (Kameshwara and Shukla, 2017). As such, various research projects ensued investigating the aforementioned. Another social justice topic researched underscored the role of education or the lack thereof in predicting the propensity to commit a criminal offence. Other social justice projects undertaken focused on cultural intelligence, and religious discrimination.

\section{Process reflection}

This section focuses on the analysis of student feedback as it relates to the teaching of the subject research methodology. The pedagogical underpinning of the lecturer's teaching vision subsumes a pro-active learnercentred approach based on a constructivist paradigm implored by many in the field of education with an underlying systems theory perspective. As such, the Systems Theory Framework (STF) allows for the broader context in which students exist to be taken into consideration (Patton and McMahon, 2006). Per se, the STF is deemed a dynamic system comprising out of content and process influences. Content influences subsume inherent personal qualities and characteristics as well as the interaction between the before mentioned with the external environment on an individual at an environmental or societal level. Content influences refer to re-cursiveness i.e. interaction between influences, depending on change over time and chance (McMahon and Watson, 2009). Thus, interaction between the inherent characteristics of the student and the intervention by the lecturer can be categorized as a content influence on a societal level. Furthermore, the current impetus on "afropolitanism" (viz. the voice of the student as a fundamental aspect of teaching), within the framework of a democracy which encompasses freedom of expression (University of Cape Town, 2013) was the rationale for the analysis of student evaluations in a portfolio of evidence. Thus, in view of the emancipatory nature of the aforementioned, it becomes evident that students should be deemed an integral part of the success of a learning program and cannot be perceived as mere passive agents during the process.

Against this background, a brief overview of some of the accepted objectives of a Teaching and Learning Strategy (University of Cape Town, 2013) taken from one of the foremost universities in the South African context was utilized as benchmark and will be highlighted with example as well as student excerpt.

\section{Providing a flexible and supportive curriculum framework}

The first theme underscore providing a flexible and supportive curriculum framework that caters for a wide diversity of educational preparedness. One possible way to achieve afore said, is inter alia, designing curricula which support students through key phase of transitioning (viz. transitioning from undergraduate to postgraduate studies; transitioning from high school to university; transitioning from university to the workplace) (University of Cape Town, 2013). Regarding the first mentioned, viz. transitioning from undergraduate to postgraduate studies, research methodology is pivotal. As such one Honours student noted: "This is an excellent course in preparation for M. Tech." With reference to the transitioning from high school to university, the context of individual students is paramount and educators should be cognizant of the STF framework in order to adjust teaching skills to cater for diverse levels of preparedness. As such, a postgraduate 
student noted: "the lecturer is easily approachable and understanding towards my short comings. She communicates easily with her students without any ambiguities and her students understand her methods of teaching or supervision methods." This excerpt underscores the importance of adjusting teaching methods to accommodate various levels of preparedness. On the other hand, there are student who might need additional assistance, for example: "The lecturer is too fast. Try to accommodate other students who might be slow. In any case I enjoy the subject very much." These students should be identified early to ensure appropriate just in time interventions. In terms of the transitioning from university to the workplace curricula should ideally include employability skills which subsume graduate attributes and critical cross field outcomes to ensure graduate employability after completion of higher education qualifications. An additional way this objective could be achieved is by ensuring that curricula have a coherent structure. To this end one PhD candidate noted: "the supervisor has prepared a student research project manual which ensured early focus on the project, established timelines and outcomes for the research. Afore said also provided [.......] practical writing resources which were invaluable to me as an early career researcher."

\section{Promoting teaching approaches, materials and assessment practices}

The second theme emphasizes promoting course design, teaching approaches, teaching materials and assessment practices that are effective for a diverse student body and range of learning contexts. Various ways could potentially be identified, inter alia, facilitating early assessment and feedback, providing additional student learning support where appropriate and facilitating learning-centred teaching to mention a few (University of Cape Town, 2013). In terms of facilitating early assessment and feedback a PhD candidate noted: "the supervisor provided very clear and prompt feedback on written work." Moreover, $62.2 \%(n=28)$ of the Honours students noted that the lecturer always provided useful feedback when returning tests and assignment. A further $31.1 \%$ (n $=14$ ) of the sample indicated that afore said transpire regularly. In terms of providing additional student learning support where appropriate, a PhD candidate noted: "the supervisor provided [.......] practical writing resources which were invaluable to me as an early career researcher." Another postgraduate student mention that: "the lecturer is always willing to go beyond the point of call, always available although she has a busy schedule." While, an Honours student used the following description: "She has a heart to assist always with a smile, no matter when you ask or just visit her office without a set appointment she is willing to help." The last aspect refers to facilitating learning-centred teaching methods, which underscore incorporating the views of students into the learning process as active participants. As such, 64.6\% $(n=31)$ of the Honours sample noted that the lecturer always encouraged students to ask questions and express ideas, while a further $29.9 \%(n=14)$ mentioned that this practice took place regularly. It should also be noted that an overwhelming majority, 93.8\% ( $n=45)$, indicated that the lecturer always treated students with respect.

\section{Providing support, structure and promote usage of educational technologies}

The third theme highlight providing support, structure and promote the use of educational technology where it aims to improve the quality of teaching and learning. Two proposed ways to achieve this objective subsume enabling greater engagement particularly for large classes and promoting flexibility in catering for diversity (University of Cape Town, 2013). As such, 97.9\% ( $n=$ 47) of the sample indicated the use of an online component (i.e. educational technology) in the mentioned course which consisted out of uploading the course content online to foster greater accessibility. Additionally, previous assessment papers were also uploaded to assist students with examination preparation. Students could engage online with the lecturer and a community of practice was established.

\section{Supporting graduates with potential through the transition to postgraduate studies}

The fourth theme underscores supporting graduates with potential through the transition into and completion of postgraduate studies. Various ways could possibly be identified, inter alia, developing the research capabilities of postgraduate students, piloting different models of supervision and research training responsive to changing contexts and promoting opportunities for postgraduates to present at conferences and to publish (University of Cape Town, 2013). In terms of the first mentioned, a PhD candidate noted: "the supervisor prepared a student research project manual which ensured early focus on the project, established timelines and outcomes for the research." The use of a reflective journal was encouraged and an example was provided within the project manual. Similarly, the project manual also contained a written agreement between the candidate and the supervisor delineating the roles and responsibility of each. It is pivotal to address expectations at the onset of the supervisor/postgraduate student relationship. At the inception of the relationship regular meeting were scheduled to discuss the reflective journal and assist students in the transitioning phase. In terms of piloting different models, the respondent conducted a research study to explore postgraduate student's perceptions on research supervision with the development of different 
models in mind. Lastly, postgraduate students are encouraged to publish and assisted, for example research colloquia are arranged to disseminate knowledge.

\section{Creating an enabling learning environment}

The fifth theme focuses on creating and sustaining an enabling learning environment for undergraduate and postgraduate students by means of strengthening the tutorial and practical learning experience and offering psycho-social and material support (University of Cape Town, 2013). In a sample of Honours students, $56.2 \%$ (n $=27$ ) indicated that the lecturer always used practical examples to explain the learning material, while a further $31.2 \%(n=15)$ said this practice occurred on a regular basis. Moreover, $51.1 \%(n=24)$ noted that the practical examples were always useful to the course, whereas $29.8 \%(n=14)$ indicated that the examples were regularly useful. In terms of the narrative responses, a respondent noted: "the lecturer even makes a lot of examples so that we can see or understand what she talks about." With reference to psycho-social support it is the firm believe that an educator should be approachable in order to be in a position to provide assistance. As such, a PhD candidate noted: "As a supervisor I found [the supervisor] to be well organized, approachable, with strong subject knowledge." A Master's degree student wrote: "She is easily approachable..." Similarly, an Honours student mentioned that: "the lecturer is approachable and understandable."

Despite, being a staunch supporter of the learnercentric approach which advocate for the student's perceptive and voice to be heard as illustrated above it is also pivotal to provide an indication of the views of colleagues. A senior researcher at an international research institute noted: "I was from the start very impressed by [her] energetic intelligence, meaning her capacity to relate and directly work with the energy present in a team of many researchers with different disciplines." A Head of Department noted that: "I can, without hesitation, endorse [her] astonishing capability to share her academic expertise with her students, as well as her ability to inspire her students to the next level."

\section{Critical or premise reflection}

This section emphasizes the hegemonic assumptions that are embraced and therefore important in as far as it relates to career planning and development. It should be noted that the reflections was drawn from the academic profile, student feedback as well as coaching sessions.

The academic profile reveals a concentrated emphasis on focused scientific research encompassing a variety of topics mainly in the field of psychology. A further observation was that most of the research utilises a quantitative design. This was congruent with the lecturing endeavours in research methodology. The lecturer gives emphasis to adding to the body of knowledge based on the post-positivist paradigm. Hence, research methodology lecturing and academic research can be deemed harmonious with this internal driving force. As a result career management activities should include planning and development centred on these core tenets. Additionally, career anxiety might occur if there is significant deviation from the aforementioned.

There was an expressed notion that, ascribed to the lack of adequate learner support during the onset of academic career endeavours the incumbent is passionate to provide intensive learners support as acknowledged by students. Hence, learner support is not compliance driven but rather emanates from an inner, value based source which further aims to bring about social justice. The aforementioned is aligned to the current strong impetus for an African Renaissance in educational discourse propagating that transformative educators should embrace an indigenous socio-cultural and epistemological framework (Higgs, 2013). Furthermore, it came to the fore that the lecturer while being a student was exposed to lecturers enforcing own ideas on students which clashed with innate belief systems. As a result there is a strong impetus to implement an approach which assist students to find their own voice and to apply their own ideas in their respective fields of study.

\section{DISCUSSION}

The findings above represent the application of the Comprehensive Assessment Method in Psychology (CAMP) incorporating an academic portfolio and a selfreflection exercise. Table 1 provides an integrated summary of the thematic analysis.

The value of reflective observations was accentuated by van Coller and de Coning (2016) who noted that reflection revealed content which was previously not explicit. The said content sets the foundation for the third step in the experiential learning cycle of Kolb (1984), namely abstract conceptualisation.

\section{CONCLUSION}

The purpose of this article was to explore the extension of the Comprehensive Assessment Method in Psychology (CAMP) to educational practices within the mentioned field by implementing a portfolio of evidence and self-reflection, which are the two main components of the model. The CAMP model was found to be useful ascribe to the distilling of key focus areas within academic endeavours which can be compared with the 
Table 1. Key findings from the thematic analysis.

\begin{abstract}
Area of research and reflective observations
Reflection on own research outputs

Sub-theme 1: Educational composition of the population

A lack of effective career guidance exists at secondary school level.

\section{Sub-theme 2: Graduate unemployment}

The unemployment rate of graduates in South Africa increased by an estimated $50 \%$ between 1995 and 2005, which makes it the fastest growing unemployment rate.

\section{Sub-theme 3: Educational Quality}

Research indicated that there was no statistically significant association between skills development in higher education institutions and increased probability of employment.
\end{abstract}

\section{Sub-theme 4: Social Justice}

The main objective of social justice through the lens of psychology would be to address the social, political, and economic conditions that impede development of individuals, families, and communities.
Suggested interventions

Provision of effective career counselling to adequately inform learners about vocational availability as well as subject requirements.

A research project ensued to investigate this phenomenon with a book chapter, conference papers and academic journal articles as research outputs.

A research project was undertaken to ensure that graduates are employable and ultimately meet the expectations of employers.

Various research projects ensued investigating the aforementioned focusing on cultural intelligence and religious discrimination.

\section{Reflection on student feedback}

Providing a flexible and supportive curriculum framework

Importance of adjusting teaching methods to Designing curricula which support students through key accommodate various levels of preparedness.

There are student who might need additional should be identified early to ensure appropriate just in assistance. time interventions.

\section{Promoting teaching approaches, materials and assessment practices}

Promoting quality course design, teaching approaches, teaching materials and assessment practices that are

Early assessment and feedback as well as utilising effective for a diverse student body and range of learning contexts.

\section{Supporting graduates with potential through the transition to postgraduate studies}

A low proportion of graduates successfully transition into and complete their post-graduate studies.

\section{Creating an enabling learning environment}

The learning environment is an important variable in learner success.

\section{Critical reflection on own hegemonic assumptions}

Experiences as a student significantly influence the lecturers' teaching and should be continuously reflected upon.
Various intervention could be identified, for example, developing research capabilities, piloting different supervision models and promoting opportunities for postgraduates to present at conferences and to publish

Creating and sustaining an enabling learning environment for undergraduate and postgraduate students by means of strengthening the tutorial and practical learning experience and offering psycho-social and material support.

Continual alignment of underlying assumptions with current career environment and career management practice. research focus of the department to ensure individual and organizational alignment. Furthermore, key themes obtained by means of student evaluation feedback could be benchmarked against the organizational strategic intent as well as identify possible areas of development for the lecturer.
Thus, the CAMP model could potentially be utilized as a performance assessment tool for tertiary institutions. The current utilization of a student evaluation questionnaire could be expanded on by conducting indepth evaluations of overall performance. To achieve this objective, the tertiary institution's faculty officer could 
manage the monitoring and evaluation of lecturers to ensure quality pedagogical practices. Lecturers could furthermore be requested to include personal reflections in order to institutionalise reflective practice. An institutionalised application of reflection is predestined to not only improve the quality of teaching and learning but also to enhance artistry through reflection-on-action, which consists of thinking back on behaviour in order to gain new insights.

Higher education institutions and individual practitioners could benefits from this kind of research as it assists with career planning and development and provides the organisation with rare insight into the institutional alignment of lecturers.

\section{REFERENCES}

Billings D (2007). Teaching for transfer of core/key skills in higher education: cognitive skills. Higher Educ. 53:483-516.

Bourner T (2003). Assessing reflective learning. Educ. Train. 45(5):267-272.

Brookfield S (1995). Becoming a critically reflective teacher. San Francisco, CA: Jossey- Bass.

Crucil C, Amundson N (2017). Throwing a Wrench in the Work(s): Using Multicultural and Social Justice Competency to Develop a Social Justice-Oriented Employment Counselling Toolbox. J. Employ. Counsell. 54(1):2-11.

Dahlberg K, Drew N, Nystrom M (2008). Reflective lifeworld research. Lund, Sweden: Student literature AB.

De Coning $\mathbf{R}$ (2014). The perceived value of reflective practice on the learning journey of the Master of Philosophy in Management Coaching student. Unpublished Masters Dissertation. University of Stellenbosch, South Africa.

Development Policy Research Unit (DPRU) (2007). Graduate unemployment in the face of skill shortages: a labour market paradox. DPRU Policy Brief Series. School of Economics. University of Cape Town, Cape Town.

Dewey J (1997). How we think. New York: Dover.

Dewey J (1916). Democracy and education. New York: The Macmillan Company.

Erasmus J, Breir M (2009). Skills Shortages in South Africa: Case studies of key professions. Cape Town: Human Science Research Council.

Goujon A, Lutz W, Wazir A (2011). Alternative population and education trajectories for Pakistan. IIASA Interim Report, IR-11-029.

Groff J (2013). Technology-rich innovative learning environments. OCED CERI Innovative Learning Environment project. Retrieved from www.oecd.org/.../Technology-Rich\%20Innovative\%20Learning\%20Environments\%2. [Accessed 10 October 2018].

Higgs $P$ (2013). African philosophy and the transformation of educational discourse in South Africa. J. Educ. 30:5-22.

Hinchliffe GW, Jolly A (2011). Graduate identity and employability. Brit. Educ. Res. J. 37(4):563-584.

Howard TC (2003). Culturally relevant pedagogy: ingredients for critical reflection. Theor. Pract. 42(3):195-202.

Jonck P (2014). The mitigating effect of work-integrated learning on graduate employment in South Africa. Afr. Educ. Rev. 11(3):277-291.

Jonck P, Minnaar R (2015). Validating an employer graduateemployability skills questionnaire in the faculty of Management Sciences. Mediterranean J. Soc. Sci. 6(2):230-237.

Jonck P, Van der Walt F (2015). Graduate employability skills: differences between the private and the public sector in South Africa. Mediterranean J. Soc. Sci. 6(3):345-352.

Kameshwara KK, Shukla T (2017). Towards social justice in institutions of higher learning: addressing gender inequality in science and technology through capability approach. Administrative Sciences. $7(22): 1-13$.
Kember D, Jones A, Loke A, McKay J, Sinclair K, Tse H, Webb C, Wong F, Wong M, Yeung E (1999). Determining the level of reflective thinking from students' written journals using a coding scheme based on the work of Mezirow. International J. Life-Long Learn. 18(1):18-30.

Kolb DA (1984). Experiential Learning: Experience as the Source of Learning and Development. Englewood Cliffs, N.J: Prentice-Hall.

Leijen A, Valtna K, Leijen DAJ, Pedaste M (2012). How to determine the quality of students' reflections. Stud. Higher Educ. 37(2):203-217.

Leitch R, Day C (2000). Action research and reflective practice: towards a holistic view. Educ. Action Res. 8(1):179-193.

Lewis D, Virden T, Hutchings PS, Bhargava R (2011). Competence assessment in integrating reflective practice in a professional psychology program. J. Scholar. Teach. Learn. 11(3):86-106.

Lombardi J (2008). To portfolio or not to portfolio: Helpful or hyped? Coll. Teach. 56:7-10.

Mälkki K, Lindblom-Ylänne S (2012). From reflection to action? Barriers and bridges between higher education teachers' thoughts and actions. Stud. Higher Educ. 37(1):33-50.

McMahon M, Watson M (2009). Career psychology research challenges: a systems theory response. South Afr. J. Psychol. 39(2):184.

Merryfield MM (1993). Reflective practice in global education: strategies for teacher educators. Theor. Pract. 32(1):27-32.

Mezirow J (1998). On critical reflection. Adult Educ. Quart. 48(3):185198.

Mezirow J (2008). An overview on transformative learning. In K. Illeris (Ed), Contemporary theories of learning theorists in their own words. London: Routledge.

Moon JA (2013). Reflection in learning and professional development. New York: Routledge-Falmer.

Mortari L (2015). Reflectivity in Research Practice. Int. J. Qualitat. Methods. 14(5):1-9.

Oppedisano V (2011). The (adverse) effects of expanding higher education: evidence from Italy. Econ. Educ. Rev. 30(5):997-1008.

Patton W, McMahon M (2006). Career development and systems theory: Connecting theory and practice. Rotterdam, Sense Publishers.

Ratts MJ (2009). Social justice counselling: Toward the development of a fifth force among counselling paradigms. J. Human. Counsell. 48:160-173.

Rodgers C (2002). Defining reflection: Another look at John Dewey and reflective thinking. Teach. Coll. Record. 4(4):842-866.

Saltiel D (2007). Judgment, narrative and discourse: Critiquing reflective practice. Retrieved from http://www.leeds.ac.uk/medicine/meu/lifelong06/papers/P_DavidSalti el.pdf [Accessed 10 October 2018].

Schön DA (1987). Educating the reflective practitioner: towards a new design for teaching and learning professions. San Francisco: JosseyBass.

Schön DA (1983). The reflective practitioner. New York: Basic Books.

Shulman L (1987). Knowledge and Teaching: foundations of the new reform. Harvard Educ. Rev. 57(1):1-22.

University of Cape Town. (2013). Teaching and learning at UCT. Cape Town.

Van Coller S, De Coning $\mathbf{R}$ (2016). The perceived value of reflective practice on the learning journey of the M Phil in Management Coaching student. J. Coach. Consult. Coach. Psychol. Afr. 2:51-71.

Van der Merwe BC (2007). A model for student evaluation to enhance teaching and learning quality at the Central University of Technology, Free State. Unpublished doctoral thesis. University of the Free State. http://scholar.ufs.ac.za:8080/xmlui/handle/11660/2042. [Accessed 10 October 2018].

Varela FJ, Thompson E, Rosch E (1991). The embodied mind: Cognitive science and human experience. MIT Press, Cambridge. Retrieved from http://cepa.info/1969. [Accessed 10 October 2018].

http://sciencewebpublishing.net/jerr 